\title{
Carbon Monoxide: The Other Silent Killer
}

Kirk L. Cumpston, DO; S. Rutherfoord Rose, PharmD

\section{Although there has been a significant decline in the number of deaths associated with unintentional and intentional $\mathrm{CO}$ toxicity, ED visits due to $\mathrm{CO}$ exposure remain a common presentation, especially during the winter months, and must be considered in the differential diagnosis of indiscriminate symptoms.}

\section{Case Presentations}

\section{Case 1: Smoke Inhalation} (Carbon Monoxide and Cyanide)

A 50-year-old woman was pulled from the window of a burning building and found to be in cardiac arrest with pulseless electrical activity. Standard advanced cardiac life-support was started, and infusion of intra-osseous hydroxocobalamin (OHCob) was administered at the time of intubation because of the concern for cyanide $(\mathrm{CN})$ gas exposure during smoke inhalation. Return of spontaneous circulation occurred before arrival at the hospital.

Upon presentation to the ED, the patient's vital signs were: initial blood pressure (BP), 92/47 mm Hg; heart rate (HR), 112 beats/min; respiratory rate (RR), 31 breaths/min; and temperature $(\mathrm{T}), 99.7^{\circ} \mathrm{F}$.
Following intubation, the patient's oxygen saturation $\left(\mathrm{SaO}_{2}\right)$ on pulse oximetry (POX) was $93 \%$, and her fraction of inspired oxygen $\left(\mathrm{FiO}_{2}\right)$ was $100 \%$.

On physical examination, the patient's face was covered with soot. The lung sounds were equal and clear to auscultation bilaterally. The neurological examination was significant for a Glasgow Coma Scale of 3, without administered sedation, and there were no signs of dermal burns. Initial arterial blood gas (ABG) results were: $\mathrm{pH}, 7.06$; carbon dioxide partial pressure $\left(\mathrm{PCO}_{2}\right), 58 \mathrm{~mm} \mathrm{Hg}$; partial pressure of oxygen $\left(\mathrm{PO}_{2}\right), 152 \mathrm{~mm} \mathrm{Hg}$; bicarbonate $\left(\mathrm{HCO}_{3}\right)$, $17 \mathrm{~mm} \mathrm{Hg} ; \mathrm{SaO}_{2}, 98 \%$ (after intubation); $\mathrm{FiO}_{2}, 100 \%$; carboxyhemoglobin (COHb), $30 \%$; and lactate, $14 \mathrm{mmol} / \mathrm{L}$.

Dr Cumpston is an associate professor, division of clinical toxicology; and medical director of the Virginia Poison Center, department of emergency medicine, both at Virginia Commonwealth University, Richmond. Dr Rose is a professor and chair, division of clinical toxicology; and director, Virginia Poison Center, department of emergency medicine, both at Virginia Commonwealth University, Richmond.

Authors' Disclosure Statement: The authors report no actual or potential conflict of interest in relation to this article.

DOI: 10.12788/emed.2017.0065 

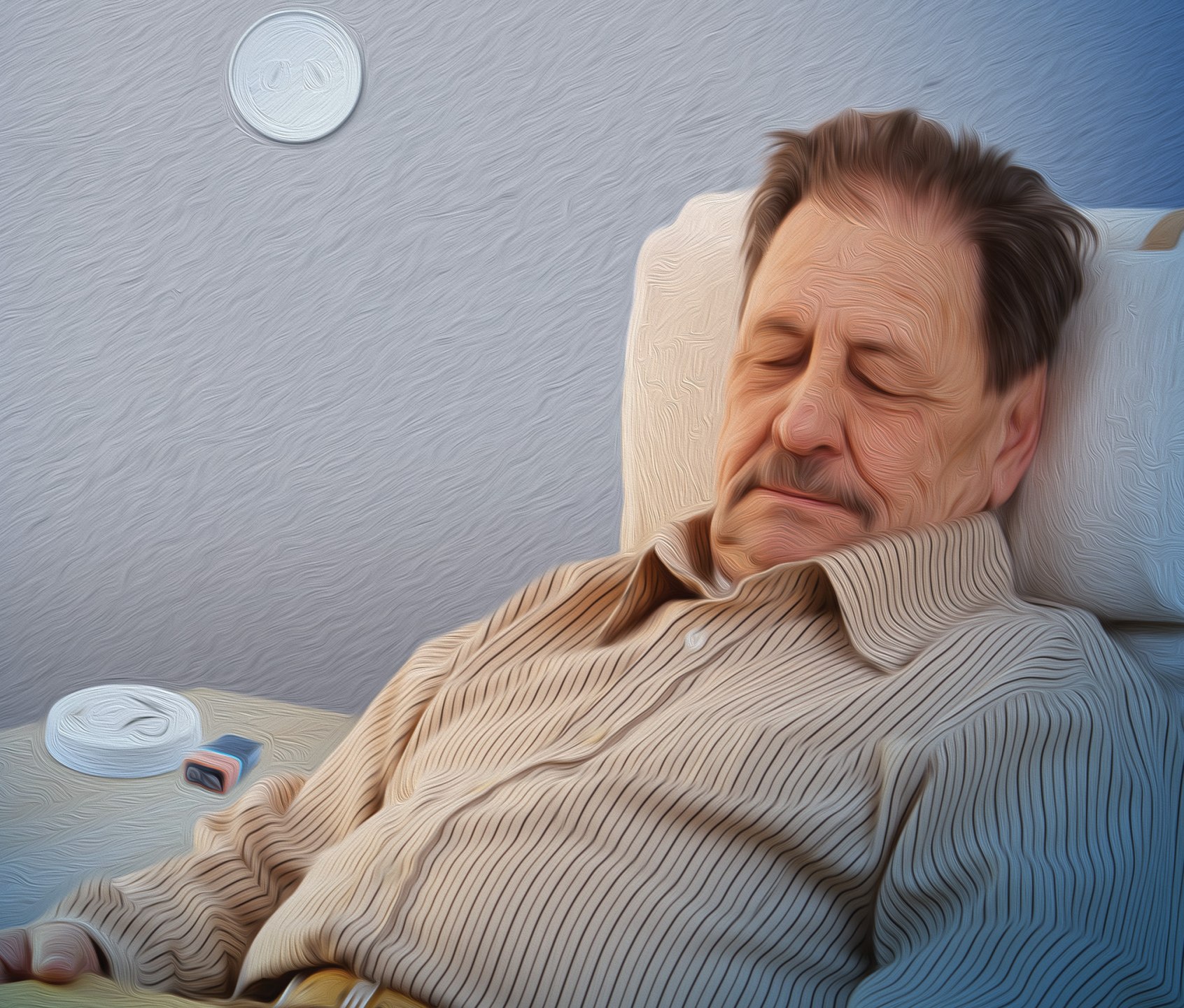
Case 2: Household Misadventure (Carbon Monoxide)

Several days after disabling the carbon monoxide (CO) detector in his home to silence the alarm that had continued to sound, a 67-year-old man developed weakness and called his local fire department. Upon arrival at the man's home, the fire department confirmed an ambient air CO gas concentration over $200 \mathrm{ppm}$. Emergency medical services (EMS) promptly brought the patient to the local ED for evaluation and treatment.

Shortly after arrival at the ED, the patient's weakness had resolved. His vital signs at examination were: $\mathrm{BP}, 154 / 85 \mathrm{~mm}$ Hg; HR, 79 beats/min; RR, 15 breaths/min; and $\mathrm{T}, 98.8^{\circ} \mathrm{F}$. The patient's $\mathrm{COHb}$ level was $28 \%$ with administration of $100 \%$ oxygen $\left(\mathrm{O}_{2}\right)$ via a nonrebreather mask (NRBM).

\section{Carbon Monoxide Toxicity}

Carbon monoxide is a toxin of considerable importance to emergency physicians (EPs). The diagnosis at times can be challenging, the interpretation of $\mathrm{COHb}$ can be confusing, and the role of hyperbaric oxygen (HBO) therapy in the treatment of CO poisoning remains controversial.

\section{Natural Sources}

Carbon monoxide is formed from the incomplete combustion of organic (carbonaceous) fuels, such as charcoal, wood, petroleum distillates (gasoline, kerosene, diesel fuel), and natural gas. Though the majority of atmospheric CO comes from natural sources (eg, volcanoes, forest fires, marsh gases), poisoning exposures are primarily due to man-made CO.

\section{Man-Made Sources}

Motor vehicle exhaust is the most abundant source of man-made CO, and exposures to exhaust fumes are common causes of both intentional and unintentional poisonings and death. Other frequent sources of CO poisoning include smoke inhalation from house fires; inadequate ventilation during use of kerosene space heaters; charcoal grills or hibachis; burning wood or charcoal; fuel-powered tools such as generators, fork lifts, and chain saws; or faulty (natural or bottled) gas appliances, such as stoves, furnaces, or water heaters (Table 1). Though propane is known to burn more cleanly than natural gas (ie, less harmful to the environment), it still can produce CO.

Though neither electrical appliances nor "gas leaks" are sources of CO, like CO, natural gas (mostly methane) and bottle gas (propane) are odorless, tasteless, and colorless. Utility companies add sulfur containing mercaptans to natural gas so that leaks can be detected, but CO is only formed when the fuel is burned in a gaspowered appliance.

\section{Endogenous Carbon Monoxide}

Endogenous CO production can occur from catabolism of heme or from hepatic metabolism of methylene chloride, but exposures to this solvent are unlikely to generate $\mathrm{COHb}$ concentrations above $10 \%$.

\section{Epidemiology}

The incidence of CO poisoning is likely more frequent than documented since many cases of minor exposures are unreported due to self-limiting effects and/or the vague, nonspecific nature of symptoms associated with minor exposures. In 2015, US Poison Control Centers reported over 14,000 cases of CO poisoning, only $43 \%$ of which were treated in a health care facility. ${ }^{1}$ The vast majority of exposures (97\%) were unintentional and resulted in 52 deaths $(0.398 \%){ }^{1}$

Data from hospitalized patients in 2007 revealed that over 200,000 ED visits and 22,000 hospitalizations were possibly associated with unintentional, non-firerelated CO exposures. ${ }^{2}$ Approximately $10 \%$ of the exposures in each of these populations were confirmed by specific International Classification of Diseases Medical E codes. ${ }^{2}$

Regardless of dataset, ED visits due to 
CO exposure are most common in young adults and women, occur in winter months from exposure in and around homes, and result in discharge from the ED. Elderly patients have the highest rate of hospital admission.

Carbon monoxide poisoning has long been considered a leading cause of poisoning death, though numbers appear to be declining, and $\mathrm{CO}$ was responsible for fewer deaths than opioids in 2017..$^{2}$ The National Center for Health Statistics reported 56,133 CO-related deaths from 1979 through 1988-an average of 5,600 per year. ${ }^{3,4}$ Of these, $46 \%$ were from suicide; $28 \%$ were related to burns or house fires; and $21 \%(11,547)$ were characterized as unintentional. Motor vehicle exhaust was associated with $57 \%$ of the unintentional deaths. A more recent analysis of unintentional exposures reported 2,244 deaths during the period of 2010 to 2015-an average of 374 deaths per year (393 in 2015). ${ }^{5}$

Preventive measures are likely responsible for the significant decline in nonfire-related CO poisoning deaths from the early 1970s through the 1990s. The introduction of catalytic converters in automobiles in 1975 and $\mathrm{O}_{2}$ sensors in 1981 eventually reduced automotive CO emissions by $95 \%$ compared to pre-1975 vehicles. ${ }^{6}$ Both unintentional death and suicide rates associated with CO from motor vehicles subsequently declined by $81 \%$ and $43 \%$, respectively. The lower decline in suicidal deaths serves as a reminder that intentional exposure to motor vehicles remains dangerous and potentially lethal.

\section{Pathophysiology/Mechanisms of Toxicity}

Carbon monoxide is a colorless, odorless gas that readily reaches the bloodstream during alveolar gas exchange. Since absorption is rapid, exposures to high CO concentrations can produce toxicity within minutes, though exposure severity is related to both inspired CO concentration and duration of exposure.

\section{Table 1. Common Sources of Carbon Monoxide Poisoning}

Smoke inhalation

Gas- and diesel-powered motor vehicles

Gas generators

Gas stoves, furnaces, and water heaters

Charcoal grills, hibachis

Wood-burning stoves and fireplaces

Gas-powered fireplaces

Kerosene-powered space heaters

Monster truck rallies

Ice resurfacing machines (ie, Zamboni)

Sitting in the back of pick-up trucks

Houseboats

Inner-tubing behind fuel-powered boats

Mud bogging

Propane-powered forklifts

Hookah smoking

Smoking nicotine or marijuana cigarettes and using vaporizer pens

Paint remover containing methylene chloride

Powerwashers

Methylene bromide

Dry carbon dioxide absorbents of inhalational anesthetics

\section{Endogenous Elimination}

Carbon monoxide is eliminated from the body in expired air, with an elimination half-life dependent on $\mathrm{FiO}_{2}$ and atmospheric pressure. Accordingly, $\mathrm{COHb}$ decreases with a half-life (all approximate) of 4 to 6 hours when patients are breathing room air $\left(21 \% \mathrm{O}_{2}\right), 60$ to 90 minutes with $\mathrm{O}_{2}$ delivery at $95 \%$ to $100 \%$, and 20 to 40 minutes under hyperbaric conditions (2.53.0 atmospheres absolute [ATA]). 


\section{Effect on Hemoglobin}

Once absorbed, CO has an affinity for hemoglobin $(\mathrm{Hb})$ that is over 200 times greater than does $\mathrm{O}_{2} \cdot{ }^{7}$ The formation of $\mathrm{COHb}$ results in both a decreased $\mathrm{O}_{2}$ carrying capacity of $\mathrm{Hb}$ at the sites where $\mathrm{O}_{2}$ would have been, and because of its new configuration, $\mathrm{COHb}$ does not allow currently bound $\mathrm{O}_{2}$ to be offloaded. This is graphically represented by a shift of the $\mathrm{O}_{2}-\mathrm{Hb}$ dissociation curve to the left. In addition, $\mathrm{CO}$ continues to be bound by other intracellular heme molecules in myoglobin of skeletal and myocardial muscle, and the cytochrome oxidase system in mitochondria. ${ }^{8}$

\section{Immunologic and Inflammatory Effects}

Carbon monoxide poisoning results in a cascade of immunologic and inflammatory effects, such as generation of nitric oxide, lipid peroxidation from neutrophils, mitochondrial oxidative stress, and apoptosis. These effects result in cellular asphyxia in all organs, but the most emergent lifethreatening concerns are ischemia to the brain and heart.

\section{Severity of Toxicity and Exposure}

As previously noted, the severity of CO poisoning is dose-dependent, meaning that it is related to the concentration of CO in inspired air and the duration of the exposure. Carbon monoxide is typically absent in fresh air, but levels may approach 2 to $5 \mathrm{ppm}$ due to cooking, wood burning, mild air pollution, etc. The source of levels above 5 ppm should generally be investigated.

Maximum safe exposure levels for workers over an 8-hour period range from 25 to $50 \mathrm{ppm}$. Exposures to CO levels above 50 to $100 \mathrm{ppm}$ are likely to elicit symptoms in most patients, depending on duration of the exposure. Carbon monoxide levels of $200 \mathrm{ppm}$ may result in a mild headache after 2 to 3 hours of exposure, and a more severe headache and nausea after 1 to 2 hours of exposures to $400 \mathrm{ppm}$ of CO.
Accordingly, home CO detectors use a combination of ppm and time for alarms, and they may not sound an alarm at 40 ppm until the level persists for 8 or so hours. Home CO detectors, however, will sound an alarm immediately when a level of 80 to $100 \mathrm{ppm}$ is reached.

\section{Clinical Presentation}

\section{Acute Exposure}

Acute exposure to $\mathrm{CO}$ causes a variety of effects that are largely nonspecific, as there is no toxic syndrome (toxidrome) considered pathognomonic for CO poisoning. Ambient CO levels, duration of exposure, minute ventilation, presence of other toxic gases, and patient comorbidities can all contribute to the severity of exposure and presenting signs and symptoms. Effects associated with mild poisoning include headache, dizziness, blurred vision, fatigue or weakness, nausea, and shortness of breath. Patients with pre-existing respiratory, cardiovascular (CV), or neurological compromise are likely to present with more pronounced symptoms. In either case, these complaints may easily be confused with a viral illness, emphasizing the importance of eliciting a history of potential exposure to CO, particularly when multiple patients are involved.

As the concentration of $\mathrm{COHb}$ increases, more significant clinical effects can be expected, including tachycardia, chest pain, hypotension, dysrhythmias, lethargy, coma, apnea, and seizures. Hypoxia can result in myocardial injury, cerebral edema, stroke, and acute pulmonary and kidney injury.

Following acute exposure, the severity of effects correlates with the peak pretreatment $\mathrm{COHb}$ concentration. However, the peak concentration is usually unknown, since most patients with significant exposures will have some time period elapsed between the exposure and the determination of $\mathrm{COHb}$, and the $\mathrm{COHb}$ will have declined at a rate depending on $\mathrm{FiO}_{2}$ and minute ventilation. In these circumstanc- 
es, $\mathrm{COHb}$ is a poor indicator for HBO therapy and outcome.

\section{Delayed Neurological Sequelae}

Persistent, recurrent, or delayed (following period of no symptoms) neurological effects can occur in up to $40 \%$ of cases, and patients with significant exposures (eg, loss of consciousness) appear to be at greatest risk. These effects most often occur within the first 3 weeks following exposure, and have been known to persist for months to years. Such effects include headache, dizziness, impaired memory or cognition, and emotional lability. Predicting which factors in CO exposure and/or treatments can be modified to prevent neurological sequelae remains challenging.

\section{Diagnostic Testing \\ Pulse Co-oximetry}

Prehospital care POX typically reads $\mathrm{COHb}$ as oxyhemoglobin, thereby displaying a normal $\mathrm{SaO}_{2} \cdot{ }^{9}$ Noninvasive $\mathrm{CO}$ pulse co-oximetry using a pulse oximeter (Rad-57, Masimo Corporation) provides a reading between -6 to +4 of the true $\mathrm{COHb}$ with a false-positive rate of $11 \%$ and falsenegative rate of $46 \%{ }^{10}$ This high falsenegative rate makes noninvasive $\mathrm{CO}$ pulse co-oximetry a poor tool to rule out a CO exposure. ${ }^{11}$ If $\mathrm{OHCob}$ has been administered due to concerns for $\mathrm{CN}$ poisoning (smoke inhalation), concentrations of $\mathrm{COHb}$ detected by a co-oximeter medical device may be decreased, as noted by a mean decrease of $1 \%$ in healthy volunteers exposed to OHCob only. ${ }^{12}$

\section{Venous and Arterial Blood Gas Testing}

For a patient in the hospital, exposure to CO can rapidly be determined using cooximetry to measure $\mathrm{COHb}$ in a venous or arterial sample. Obtaining a venous sample may be a more practical approach, as other venous measurements will likely also be obtained. Baseline "normal" COHb levels should be less than $5 \%$, but may be up to $8 \%$ to $10 \%$ in tobacco smokers.

\section{Other Laboratory Studies}

Other important laboratory tests that should be obtained are a complete blood count, lactate level, venous blood gas, and basic metabolic panel (to assess acid/base status). In two retrospective studies of patients exposed to CO, elevated lactate levels were associated with altered mental status. ${ }^{13,14}$ However, elevated lactate levels were not seen in a majority of patients with $\mathrm{CO}$ poisoning.

In addition, CN exposure should be considered when the lactate level is greater than $8 \mathrm{mmol} / \mathrm{L}$, particularly in patients with smoke inhalation. ${ }^{15}$ Troponin I and creatinine phosphokinase tests can be used to screen for myocardial or skeletal muscle injury.

\section{Effect of Hydroxocobalamin on Laboratory Evaluation}

It is important to be cautious when interpreting the results of laboratory studies in patients who have been given OHCob due to the potential co-exposure to $\mathrm{CN}$ (smoke inhalation). The red discoloration of body fluids after OHCob administration makes laboratory evaluation by spectrophotometric techniques erroneous. ${ }^{16}$ Of greatest concern is the accuracy of $\mathrm{COHb}$ concentrations. ${ }^{17}$ In a study using rabbit models by Lee et al, ${ }^{17}$ OHCob administration was shown to falsely increase $\mathrm{COHb}$ concentrations.

Livshits et $\mathrm{al}^{18}$ reported conflicting effects on $\mathrm{COHb}$ in two human cases. In the first case, the patient's true $\mathrm{COHb}$ was $93 \%$ lower (2.5\% vs $34.9 \%$ ) following administration of $5 \mathrm{~g}$ of OHCob, as measured with a rapid blood gas analyzer. In the second patient, $\mathrm{COHb}$ was $76 \%$ lower $(10.7 \%$ vs $44 \%$ ) following OHCob administration, which was also measured by a blood gas analyzer. Both of these cases illustrate lower true $\mathrm{COHb}$ concentrations than would be expected following the administration of only supplemental $\mathrm{O}_{2}$.

In a controlled experiment by Pace et al ${ }^{19}$ examining the effects of OHCob on
It is important to be cautious

\section{when}

interpreting the results of laboratory studies in patients who have been given $\mathrm{OHCob}$ due to the potential co-exposure to CN (smoke inhalation). 
measurement of $\mathrm{COHb}$ at both physiological (3\%) and pathological (30\% and 50\%) concentrations in human blood samples, the degree of interference depended on the type of co-oximeter used, the degree of $\mathrm{COHb}$ elevation (at pathological levels only), and the concentration of OHCob added. Other studies, including an evaluation of OHCob interference by Carlsson et $\mathrm{al}^{20}$ using nine different analyzers have confirmed the interference of OHCob on photometric assays. Of particular clinical importance, a falsely increased lactate level was seen after true lactate levels were found to be below $4.8 \mathrm{mmol} / \mathrm{L}$ (but not greater) using spectrophotometric or electrochemical detection. ${ }^{21}$ This increase in the false-positive assessment of the degree of toxicity could lead unnecessary escalation of care.

These studies emphasize the need to exercise caution when interpreting laboratory test results following OHCob administration. Ideally, it would be best if blood

\section{Clinical Pearls}

Suspect carbon monoxide (CO) poisoning during any season or setting when hydrocarbon fuels are being burned.

Multi-organ effects can occur since $\mathrm{CO}$ binds to heme in the cytochrome oxidase system and to myoglobin in skeletal and cardiac muscle.

Do not use noninvasive pulse oximetry to rule out a possible CO exposure.

If hydroxocobalamin (OHCob) has been administered prior to obtaining laboratory specimens, results may be inaccurate.

Hyperbaric oxygen (HBO) therapy may prevent neuropsychiatric sequelae. However, superiority over normobaric oxygen is not definitive. Like many situations in emergency medicine, the decision to initiate HBO therapy should be considered after analysis of the risks, benefits, and practical limitations.

Hydroxocobalamin is not indicated to treat $\mathrm{CO}$ poisoning. In the setting of smoke inhalation, if serum lactate is $>8-10 \mathrm{mmol} / \mathrm{L}$, and $\mathrm{pH}$ is $<7.2$, or if hypotension, dysrhythmias or seizures are present, $\mathrm{OHCob}$ is indicated for concomitant cyanide poisoning.

Consultation with a toxicologist or poison control center can assist emergency physicians when considering the risks and benefits of transferring patients for $\mathrm{HBO}$ therapy. samples were obtained prior to OHCob administration by EMS or in the ED, if the clinical scenario allows it.

\section{Imaging Studies}

For patients presenting after a closed-space fire, a chest radiograph will help assess for pulmonary injury. The classic finding of CO poisoning on head computed tomography (CT) and magnetic resonance imaging scans is evidence of ischemia in the basal ganglia. The radiographic findings may help determine the diagnosis of the altered mental status patient who presents without a history. An electrocardiogram (ECG) is also useful for detection of myocardial ischemia or dysrhythmias, when signs or symptoms of either are possible from history and physical or cardiac monitoring.

\section{Intentional Inhalation}

Intentional inhalation of fumes containing CO is a relatively common mechanism for suicide. In patients who survive, it is important for EPs and other providers to suspect additional means of self-harm. For example, at our institution, we have encountered several patients with selfinflicted trauma after remaining conscious following a medication overdose. Accordingly, patients who have intentionally inhaled CO should also be evaluated for occult medication poisoning (and trauma).

\section{Treatment}

The first step in treating a patient with CO poisoning occurs prior to arrival at the ED, when he or she is removed from continued exposure. The second step is assessing whether this is only a CO exposure, or a mixture of gases from combustion in a closed space, that might also contain CN. When $\mathrm{CO}$ and $\mathrm{CN}$ are combined OHCob is indicated to treat $\mathrm{CN}$ toxicity.

Additionally, if the patient is brought to the ED via EMS, $\mathrm{O}_{2}$ therapy will most likely have been initiated en route. In either case, the concentration of $\mathrm{COHb}$ may not accurately reflect the magnitude of expo- 
sure or prognosis, and should not be used to dictate the level of therapy or disposition. The patient's vital signs and clinical findings of end organ toxicity should guide the appropriate supportive care.

\section{Supplemental Oxygen Therapy}

Initial administration of $100 \% \mathrm{O}_{2}$ during assessment of airway, breathing, and circulation is the first step in accelerating the removal of $\mathrm{CO}$ from $\mathrm{Hb}$. For patients suffering from smoke inhalation, assessment and establishment of a secure airway when there are signs of soot or burns in the airway must always take precedence over other actions. Continuous cardiac monitoring, POX, observation, and establishment of intravenous access are often needed for detection and management of CV instability or change in mental status in cases of moderate-to-severe CO exposures. Mild exposures with headache, nausea, and flulike symptoms can be managed with symptomatic treatment and normobaric $\mathrm{O}_{2}$ until resolution of symptoms and improvement in $\mathrm{COHb}$ occur.

\section{Hyperbaric Oxygen Therapy}

Hyperbaric oxygen therapy involves the delivery of high-flow $\mathrm{O}_{2}$ (typically at $100 \%$ ) under increased atmospheric pressure (2.5 -3.0 ATA). Oxygen delivered at ambient air pressure (1.0 ATA) is often referred to as normobaric oxygen. Although $\mathrm{HBO}$ is best known for its ability to enhance $\mathrm{CO}$ elimination, research points to a much more eloquent mitigation of CO toxicity on the molecular level. These mechanisms include an increased amount of dissolved $\mathrm{O}_{2}$ in blood, regeneration of cytochrome oxidase, decreased leukocyte adhesion to microvascular endothelium in the brain, decreased lipid peroxidation in the brain after loss of consciousness, and preservation of adenosine triphosphate. ${ }^{22}$

For most patients, the majority-if not all-of $\mathrm{COHb}$ will be eliminated by the time they present to a suitable HBO chamber. Despite the knowledge that HBO ther- apy has a positive toxicokinetic effect by increasing the elimination of $\mathrm{CO}$, all of the major, prospective studies on the usefulness of HBO are related to prevention of neuropsychiatric sequelae mediated by immunological and inflammatory effects. The role of HBO in the treatment of CO poisoning has been debated for decades. Multiple studies that differ in methodology, patient populations, delivery of HBO treatments, and assessment of benefits fail to provide a consensus on the role of HBO therapy (Table 2). ${ }^{23-30}$

Before transferring a patient to a facility for HBO therapy, the potential risks and benefits of transport must be considered. In a 10-year retrospective study by Sloan et $\mathrm{al}^{31}$ of $297 \mathrm{CO}-$ poisoned patients (mean $\mathrm{COHb}, 38 \%$ ) $46 \%$ of patients had cardiopulmonary and neurological complications prior to HBO therapy at some point in the transfer pathway. During HBO therapy, $18 \%$ of patients had complications that included emesis, agitation requiring sedation, seizures, hypotension, tension pneumothorax, cardiac arrest, cardiac arrhythmias, and myocardial ischemia. It is therefore incumbent that personnel attending patients undergoing HBO therapy for $\mathrm{CO}$ poisoning be aware of, and able to manage, this variety of serious effects.

When an HBO chamber is at a clinical site with experts in the field and staff available 24 hours a day, the decision to utilize HBO may easily be made without obstacles. For most EPs, however, this is not the case. Locating and transferring a patient to an HBO center is typically a considerable logistical challenge. For many rural facilities, HBO is just not a timely therapeutic option. Two studies state the benefit of HBO therapy is greatest when starting within 6 hours from the end of the CO exposure..$^{24,26}$

Identifying those CO-poisoned patients who meet evidence-based criteria for HBO is difficult. Patients with mild CO poisoning will do well without $\mathrm{HBO}$, and critically ill patients will probably not consistently benefit from HBO. However, a pragmatic 
Table 2. Studies Comparing Hyperbaric Oxygen Therapy and Normobaric Oxygen Therapy

\begin{tabular}{|c|c|c|c|c|c|c|c|}
\hline Year & $\begin{array}{l}\text { Lead } \\
\text { Author }\end{array}$ & $\mathrm{N}$ & $\begin{array}{l}\text { Loss of } \\
\text { Consciousness }\end{array}$ & Study Design & HBO Delivery & Follow-up & HBO Effect \\
\hline 1989 & Raphael $^{24}$ & 629 & No & $\begin{array}{l}\text { Nonblinded; } \\
\text { randomized at } \\
12 \mathrm{~h} \text { from end of } \\
\text { CO exposure }\end{array}$ & $\begin{array}{l}1 \text { session of } 2 \mathrm{~h} \\
\text { at } 2.0 \text { ATA }\end{array}$ & $1 \mathrm{mo}$ & No benefit \\
\hline 1995 & Ducassé25 & 26 & No & $\begin{array}{l}\text { Nonblinded; } \\
\text { randomized as } \\
\text { soon as possible }\end{array}$ & $\begin{array}{l}1 \text { session of } \\
2 \mathrm{~h} \text { at } 2.5 \text { ATA }\end{array}$ & $\begin{array}{l}\text { Clinical EEG } \\
\text { abnormalities } \\
\text { at } 12 \text { h; EEG } \\
\text { abnormalities } \\
\text { at } 24 \text { h to } 21 \\
\text { d; reduced } \\
\text { cerebral blood- } \\
\text { flow reactivity to } \\
\text { acetazolamide }\end{array}$ & $\begin{array}{l}\text { Less clinical } \\
\text { abnormalities; } \\
\text { differences in } \\
\text { EEGs; greater } \\
\text { cerebral blood } \\
\text { flow }\end{array}$ \\
\hline 1995 & Thom ${ }^{26}$ & 60 & No & $\begin{array}{l}\text { Nonblinded; } \\
\text { randomized } 6 \mathrm{~h} \\
\text { from end of } \mathrm{CO} \\
\text { exposure }\end{array}$ & $\begin{array}{l}1 \text { session of } \\
30 \text { min at } 2.8 \\
\text { ATA; then } 90 \text { min } \\
\text { at } 2.0 \text { ATA }\end{array}$ & $1 \mathrm{mo}$ & $\begin{array}{l}23 \% \text { reduction } \\
\text { in DNS }\end{array}$ \\
\hline 1996 & Mathieu $^{27}$ & 575 & No & $\begin{array}{l}\text { Nonblinded; } \\
\text { randomized at } 12 \\
\text { h from end of CO } \\
\text { exposure }\end{array}$ & $\begin{array}{l}12 \mathrm{~h} \\
\text { postexposure } \\
\text { to } 90 \mathrm{~min} \text { at } \\
2.5 \text { ATA. All } \\
\text { patients were } \\
\text { discharged } \\
\text { with normal } \\
\text { neurological } \\
\text { examination }\end{array}$ & $\begin{array}{l}1,3,6, \text { and } \\
12 \mathrm{mo}\end{array}$ & $\begin{array}{l}\text { No difference at } \\
1 \text { mo; less PNS } \\
\text { in HBO group } \\
\text { at } 3 \text { mo; no } \\
\text { difference at } \\
6 \text { and } 12 \text { mo. }\end{array}$ \\
\hline 1999 & Scheinkestel28 & 191 & Yes & $\begin{array}{l}\text { Double-blinded; } \\
\text { randomized as } \\
\text { soon as possible }\end{array}$ & $\begin{array}{l}\text { 3- } 6 \text { daily } \\
\text { sessions of } 60 \\
\text { min at } \\
2.8 \text { ATA }\end{array}$ & $1 \mathrm{mo}$ & No benefit \\
\hline 2002 & Weaver $^{29}$ & 152 & Yes & $\begin{array}{l}\text { Double-blinded; } \\
\text { randomized } \leq 23 \mathrm{~h} \\
\text { after removal from } \\
\text { CO exposure }\end{array}$ & $\begin{array}{l}3 \text { sessions of } \\
100 \text { min with } \\
\text { combination of } \\
3.0 \text { and } 2.0 \text { ATA } \\
\text { within } 24 \mathrm{~h}\end{array}$ & 1.5 and $12 \mathrm{mo}$ & $\begin{array}{l}\text { Less } \\
\text { neurological } \\
\text { sequelae }\end{array}$ \\
\hline 2011 & Annane ${ }^{30}$ & 385 & Yes & $\begin{array}{l}\text { Randomized at } \\
12 \mathrm{~h} \text { from end of } \\
\mathrm{CO} \text { exposure }\end{array}$ & $\begin{array}{l}\text { No LOC: } 1 \\
\text { session of } 60 \\
\text { min at } 2.0 \text { ATA. } \\
\text { LOC: } 1 \text { or } 2 \\
\text { sessions at } \\
60 \text { min, each } \\
\text { at } 2.0 \text { ATA }\end{array}$ & $1 \mathrm{mo}$ & $\begin{array}{l}\text { No LOC: no } \\
\text { benefit } \\
\text { LOC: worse } \\
\text { outcome }\end{array}$ \\
\hline
\end{tabular}

Abbreviations: ATA, atmospheres; DNS, delayed neurological sequelae; EEG, electroencephalogram; HBO, hyperbaric oxygen; LOC, loss of consciousness; PNS, persistent neurological sequelae. 
Table 3. American College of Emergency Physicians Clinical Policy on Adult Patients with Carbon Monoxide Poisoning

\begin{tabular}{|c|c|c|}
\hline Critical Questions & Decision & Level of Evidence \\
\hline $\begin{array}{l}\text { Can noninvasive } \mathrm{COHb} \text { measurements be used } \\
\text { to accurately diagnose } \mathrm{CO} \text { toxicity? }\end{array}$ & No & Level B \\
\hline $\begin{array}{l}\text { Does HBO therapy as compared with NBO } \\
\text { therapy improve long-term neurocognitive } \\
\text { outcomes? }\end{array}$ & Remains unclear & Level B \\
\hline $\begin{array}{l}\text { Can cardiac testing be used to predict morbidity } \\
\text { or mortality? }\end{array}$ & $\begin{array}{l}\text { Obtain electrocardiogram and cardiac } \\
\text { biomarkers to identify acute myocardial injury, } \\
\text { which can predict poor outcomes }\end{array}$ & Level B \\
\hline
\end{tabular}

Abbreviations: $\mathrm{CO}$, carbon monoxide; $\mathrm{COHb}$, carboxyhemoglobin $\mathrm{HBO}$, hyperbaric oxygen; $\mathrm{NBO}$, normobaric oxygen.

solution must be considered when efficacy studies are incongruent with conflicting results. When signs of end-organ toxicity from $\mathrm{CO}$ are present, but cardiac arrest has not yet occurred and the logistics are streamlined, the benefit of HBO may outweigh the risk.

Signs of end-organ toxicity include syncope, seizures, coma, ischemic changes on ECG, and pregnancy with unresolved maternal distress or fetal distress. Although a $\mathrm{COHb}$ level greater than $25 \%$ or $15 \%$ (pregnant) alone is commonly used as an indication for HBO, this is largely based on opinion. Conversely, HBO is unlikely to be helpful in patients who have been resuscitated after CO-related cardiac arrest. ${ }^{32}$

\section{Treatment Guidelines}

The American College of Emergency Physicians recently developed a position statement regarding the management and treatment of CO poisoning. ${ }^{33}$ The clinical policy addresses several of the controversies discussed in this review, and provides a level of evidence for each response (Table 3).

\section{Case Conclusions}

\section{Case 1 (Smoke Inhalation Due to CO} and Cyanide Poisoning)

The patient in this case suffered severe CO and CN toxicity. A head CT scan revealed diffuse edema consistent with anoxic brain injury. After conferring with the family regarding the patient's condition and prognosis, the decision was made to withdraw life-sustaining therapy and support, and the patient died.

\section{Case 2 (Household Misadventure)}

The patient in this case was successfully treated with $100 \% \mathrm{O}_{2}$ via a NRBM and was subsequently discharged home within 4 hours from presentation.

\section{Conclusion}

Exposures to CO are ubiquitous due to our heavy reliance on carbon combustion, and the manifestations of CO toxicity are protean. Therefore, CO poisoning must be considered more frequently in the differential diagnosis of indiscriminant symptoms affecting the neurological, cardiac, pulmonary, and gastrointestinal systems, especially when multiple patients have similar symptoms.

The diagnosis of $\mathrm{CO}$ poisoning is straightforward when a serum $\mathrm{COHb}$ level is obtained on a venous or arterial blood sample. Treatment starts when the patient is removed from further $\mathrm{CO}$ exposure and breaths normobaric oxygen at ambient levels or supplemented. Because there is no clear evidenced-based indication for HBO therapy, further treatment with HBO is naturally limited by rational constraints. 


\section{References}

1. Mowry JB, Spyker DA, Brooks DE, Zimmerman A, Schauben JL. 2015 Annual Report of the American Association of Poison Control Centers' National Poison Data System (NPDS): 33rd Annual Report. Clin Toxicol. 2016;54(10):924-1109. doi:10.1080/155 63650.2016.1245421.

2. Iqbal S, Law HZ, Clower JH, Yip FY, Elixhauser A. Hospital burden of unintentional carbon monoxide poisoning in the United States, 2007. Am J Emerg Med. 2012;30(5):657-664. doi:10.1016/j. ajem.2011.03.003.

3. Cobb N, Etzel RA. Unintentional carbon monoxiderelated deaths in the United States, 1979 through 1988. JAMA. 1991;266(5):659-663.

4. Sircar K, Clower J, Shin MK, Bailey C, King M, Yip F. Carbon monoxide poisoning deaths in the United States, 1999 to 2012. Am J Emerg Med. 2015;33(9):1140-1145. doi:10.1016/j. ajem.2015.05.002.

5. Centers for Disease Control and Prevention. Environmental Public Health Tracking Network. Carbon monoxide poisoning emergency department visits. https://ephtracking.cdc.gov/showHome.action. Updated September 8, 2017. Accessed October 18, 2017.

6. Mott JA, Wolfe MI, Alverson CJ, et al. National vehicle emissions policies and practices and declining US carbon monoxide-related mortality. JAMA. 2002;288(8):988-995.

7. Buckley NA, Juurlink DN, Isbister G, Bennett MH, Lavonas EJ. Hyperbaric oxygen for carbon monoxide poisoning. Cochrane Database Syst Rev. 2011;13(4):CD002041. doi:10.1002/14651858. CD002041.pub3.

8. Hampson NB, Piantadosi CA, Thom SR, Weaver LK. Practice recommendations in the diagnosis, management, and prevention of carbon monoxide poisoning. Am J Respir Crit Care Med. 2012;186(11):1095-1101. doi:10.1164/rccm.201207-1284CI.

9. Bozeman WP, Myers RA, Barish RA. Confirmation of the pulse oximetry gap in carbon monoxide poisoning. Ann of Emerg Med. 1997;30(5):608-611.

10. Zaouter C, Zavorsky GS. The measurement of carboxyhemoglobin and methemoglobin using a non-invasive pulse CO-oximeter. Respir Physiol Neurobiol. 2012;182(2-3):88-92. doi:10.1016/j.resp.2012.05.010.

11. Shamir MY, Avramovich A, Smaka T. The current status of continuous noninvasive measurement of total, carboxy, and methemoglobin concentration. Anesth Analg. 2012;114(5);972-978. doi:10.1213/ ANE.0b013e318233041a.

12. Cashin BV, Matlock AG, Kang C, Reynolds PS, Wills BK. Effect of hydroxocobalamin on surface oximetry in nonexposed humans. Prehosp Disaster Med. 2013;28(4):367-369. doi:10.1017/ S1049023X13003518

13. Moon JM, Shin MH, Chun BJ. The value of initial lactate in patients with carbon monoxide intoxication: in the emergency department. Hum Exp Toxicol. 2011;30(8):836-843. doi:10.1177/0960327110384527.

14. Doğan NÖ, Savrun A, Levent S, et al. Can initial lactate levels predict the severity of unintentional carbon monoxide poisoning? Hum Exp Toxicol 2015;34(3):324-329. doi:10.1177/0960327114538986.

15. Baud FJ, Borron SW, Mégarbane B, et al. Value of lactic acidosis in the assessment of the severity of acute cyanide poisoning. Crit Care Med. 2002;30(9):20442050. doi:10.1097/01.CCM.0000026325.65944.7D.

16. Fueyo L, Robles J, Aguilar I, Yáñez AM, Socias M, Parera M. Hemolysis index to detect degree of hydroxocobalamin interference with common laboratory tests. J Clin Lab Anal. 2017;31(5):e22089. doi:10.1002/jcla.22089.

17. Lee J, Mukai D, Kreuter K, Mahon S, Tromberg B, Brenner M. Potential interference by hydroxocobalamin on cooximetry hemoglobin measurements during cyanide and smoke inhalation treatments. Ann Emerg Med. 2007;49(6):802-805. doi:10. 
1016/j.annemergmed.2006.11.016.

18. Livshits Z, Lugassy DM, Shawn LK, Hoffman RS. Falsely Low Carboxyhemoglobin after Hydroxocobalamin Therapy [Letter]. N Engl J Med. 2012;367(13):1270-1271. doi:10.1056/ NEJMc1114820.

19. Pace R, Bon Homme M, Hoffman RS, Lugassy D. Effects of hydroxocobalamin on carboxyhemoglobin measured under physiologic and pathologic conditions. Clin Toxicol (Phila). 2014;52(7):647-650. doi:1 $0.3109 / 15563650.2014 .939659$.

20. Carlsson CJ, Hansen HE, Hilsted L, Malm J, Ødum L, Szecsi PB. An evaluation of the interference of hydroxycobalamin with chemistry and co-oximetry tests on nine commonly used instruments. Scand J Clin Lab Invest. 2011;71(5):378-386. doi:10.3109/003 65513.2011.573573.

21. Fueyo L, Robles J, Aguilar I, Yáñez AM, Socias M, Parera M. Hemolysis index to detect degree of hydroxocobalamin interference with common laboratory tests. J Clin Lab Anal. 2017;31(5). doi:10.1002/ jcla.22089.

22. Tomaszewski C. Carbon monoxide. In: Hoffman RS, Howland MA, Lewin NA, Nelson LS, Goldfrank LR, eds. Goldfrank's Toxicologic Emergencies. 10th ed. New York, NY: McGraw-Hill; 2015:1581-1593.

23. Hampson NB, Mathieu D, Piantodosi CA et al. Carbon monoxide poisoning: interpretation of randomized clinical trials and unresolved treatment issues. Undersea Hyperb Med. 2001;28(3):157-164.

24. Raphael JC, Elkharrat D, Jars-Guincestre MC, et al. Trial of normobaric and hyperbaric oxygen for acute carbon monoxide intoxication. Lancet. 1989;2(8660):414-419.

25. Ducassé JL, Celsis P, Marc-Vergnes JP. Non-comatose patients with acute carbon monoxide poisoning: hyperbaric or normobaric oxygenation? Undersea Hyperb Med. 1995;22(1):9-15.

26. Thom SR, Taber RL, Mendiguren II, Clark JM, Hardy
KR, Fisher AB. Delayed neuropsychologic sequelae after carbon monoxide poisoning: prevention by treatment with hyperbaric oxygen. Ann Emerg Med. 1995;25(4):474-480

27. Mathieu D, Wattel F, Mathieu-Nolf M, et al. Randomized prospective study comparing the effects of HBO versus 12 hours of nbp in non comatose CO poisoned patients: results of the interim analysis. Undersea Hyperb Med. 1996;23(Suppl:7-8).

28. Scheinkestel CD, Bailey M, Myles PS, et al. Hyperbaric or normobaric oxygen for acute carbon monoxide poisoning: a randomized controlled clinical trial. Med J Aust. 1999;170(5):203-210.

29. Weaver LK, Hopkins RO, Chan KJ, et al. Hyperbaric oxygen for acute carbon monoxide poisoning. $N$ Engl J Med. 2002;347(14):1057-1067. doi:10.1056/NEJMoa013121.

30. Annane D, Chadda K, Gajdos P, Jars-Guincestre MC, Chevret S, Raphael JC. Hyperbaric oxygen therapy for acute domestic carbon monoxide poisoning: two randomized controlled trials. Intensive Care Med. 2011;37(3):486-492. doi:10.1007/s00134-010-2093-0.

31. Sloan EP, Murphy DG, Hart R, et al. Complications and protocol considerations in carbon monoxidepoisoned patients who require hyperbaric oxygen therapy: report from a ten-year experience. Ann Emerg Med. 1989;18(6):629-634.

32. Hampson NB, Zmaeff JL. Outcome of patients experiencing cardiac arrest with carbon monoxide poisoning treated with hyperbaric oxygen. Ann Emerg Med. 2001;38(1):36-41. doi:10.1067/mem.2001.115532.

33. Wolf SJ, Maloney GE, Shih RD, Shy BD, Brown MD; American College of Emergency Physicians. Clinical policy: critical issues in the evaluation and management of adult patients presenting to the emergency department with acute carbon monoxide poisoning. Ann Emerg Med. pii:S0196-0644(17)30332-3. doi:10.1016/j. annemergmed.2017.03.036. 